\title{
Staphylococcus aureus leucotoxin LukM/F' is secreted and stimulates neutralising antibody response in the course of intramammary infection
}

\author{
Pascal RAINARD* \\ INRA, UR1282 IASP, 37380 Nouzilly, France
}

(Received 8 December 2006; accepted 30 March 2007)

\begin{abstract}
Leucotoxins are regarded as virulence factors of Staphylococcus aureus, but data supporting their importance in infection are scarce. Experimental infections of the mammary glands of six goats with a leucotoxin-producing strain were used to investigate in vivo production of leucotoxin. Leucotoxin $\mathrm{M} / \mathrm{F}^{\prime}$ was monitored in milk as well as antibodies to LukM/F' in serum and milk. Leucotoxin antigen was detected by ELISA in milk samples of two goats. The appearance of neutrophils in these samples showed similarity with the altered appearance of neutrophils incubated with purified LukM/F' leucotoxin. Leucotoxic activity was found in the milk samples of these two goats, in particular those of the only goat which developed gangrenous (necrotic) mastitis, and this activity was inhibited by antibodies to LukM/F'. Increases in specific antibody titers occurred in the serum and milk of infected goats, and neutralizing titers increased in serum. The results indicate that the $l u k M$ and $l u k F^{\prime}$ genes were functional in vivo, and actively transcribed and translated in the course of mammary infection. These results suggest that LukM/F' can interfere with neutrophil defense activities during infection, and they prompt further studies to investigate the contribution of leucotoxins to staphylococcal mastitis.
\end{abstract}

Staphylococcus aureus / leucotoxin / mastitis / ruminants

\section{INTRODUCTION}

Leucotoxins are considered to be virulence factors of Staphylococcus aureus, owing to their toxic activities on several leucocytic cell types. Although direct or indirect contributions to pathogenicity are likely, data supporting the importance of staphylococcal leucotoxins in infection are scarce. Leucotoxins are bicomponent pore-forming toxins that target leucocytes, in particular neutrophilic granulocytes [15]. They constitute a family of

*Corresponding author: rainard@tours.inra.fr toxins usually designated by the first component (class $\mathrm{S}$ component) that binds to the target cell, followed by the designation of the second component (class $\mathrm{F}$ component) that associates to the cellbound first component to finally form an octameric pore: the possible homologous associations for strains of ruminant origins are the gamma hemolysins $\mathrm{Hlg} \mathrm{A} / \mathrm{B}$ and $\mathrm{HlgC} / \mathrm{B}$, and the leucotoxins LukE/D and LukM/F'. The Panton-Valentine leucotoxin (LukPVL) is rarely found in $S$. $a u$ reus strains associated with ruminant mastitis. The phagocyte-specific activity of leucotoxins would enable $S$. aureus to 
interfere with the phagocytic defenses of the host they colonize. A prerequisite for a role of leucotoxins in pathogenesis of infection is synthesis and secretion at infection foci, but evidence of in vivo leucotoxin production are scant: expression of the genes encoding two leucotoxins (luk$P V$ and $h \lg C B$ ) was found by RT-PCR in a rabbit model of $S$. aureus endophtalmitis using a strain of human origin [3], and a leucotoxin was detected in a few milk samples from cows infected by $S$. aureus [11], although its identity was not specified.

Mammary infections are a suitable model for investigating the contribution of leucotoxins to pathogenesis. The most frequently isolated pathogens in mastitis of ruminants are staphylococci, and $S$. aureus is considered a major pathogen responsible for considerable increases in milk leucocyte concentration and clinical mastitis $[2,4,18]$. Since phagocytosis by neutrophils is an important defense of the mammary gland of ruminants against mastitis-causing bacteria $[12,17]$, the production of leucotoxins may confer on $S$. aureus an increased capacity to resist host defenses and to settle in the mammary gland. Cattle mastitis field isolates are almost all equipped with genes of the leucotoxins LukE/D and hemolysin $\gamma$, and a proportion (50 to $80 \%$ ) possess the genes encoding the LukM/F' leucotoxin $[6,21]$. Data concerning mastitis isolates of goat origin are few, but indicate that LukM/F' is also well represented [16]. The most active leucotoxin on bovine neutrophils is LukM/F' [1]. Considering that this leucotoxin is widely found among ruminant mastitis isolates but not among isolates of human or other animal origins [20,21], it can be put forward that LukM/LukF' could play a distinctive role in the pathogenesis of ruminant mastitis. Owing to its high activity on neutrophils, this leucotoxin may be the counterpart in ruminants of the Panton-Valentine leucotoxin of human strains of $S$. aureus. Although the in vitro effects of several staphylococcal leucotoxins have been reported [7,9], the in vivo production of leucotoxins by $S$. aureus during infection is much less documented. In particular, their production during experimentally controlled intramammary infections has never been documented.

The aim of this study was to test whether a LukM/F'-producing strain of $S$. aureus could induce mastitis and whether leucotoxin could be detected in milk. An indirect means to assess the in vivo production of leucotoxins is to monitor the appearance of antibodies in the course of infection. That is why antibodies to LukM/F' were recorded in serum and milk following infection. The neutralizing activities of normal milk and serum, i.e. before infection, and at different times after infection, were also investigated.

\section{MATERIALS AND METHODS}

\subsection{Intramammary challenge with S. aureus}

One strain of S. aureus (Ch122), isolated from the milk of an infected goat, was used to inoculate mammary glands. This strain was selected from our strain collection on the basis of high production of LukM/F' leucotoxin [16]. It harbors the genes encoding the LukM/F', LukE/D and Hlg leucotoxins, but produces essentially LukM and LukF' when grown in vitro in conventional bacteriological media [16]. It also possesses the genes for hemolysins alpha and beta, is hemolytic on blood agar plates (strong $\beta$ hemolysis) and produces capsular polysaccharide type 8 . The strain was kept at $-70{ }^{\circ} \mathrm{C}$ in brainheart infusion broth (BHI) supplemented with 7\% dimethylsulfoxide (Sigma Chemical Co., St. Louis, MO, USA). A tube of BHI was inoculated overnight with frozen bacteria at $37^{\circ} \mathrm{C}$. Purity of the culture was checked by plating on a blood agar plate. 
From the overnight BHI culture, a subculture was made in a tube of BHI for $18 \mathrm{~h}$ at $37^{\circ} \mathrm{C}$. The bacteria were pelleted by centrifugation $\left(2000 \times g, 20{ }^{\circ} \mathrm{C}, 15 \mathrm{~min}\right)$ and washed twice with $20 \mathrm{~mL}$ of Hanks balanced salt solution (HBSS; Sigma). After the last centrifugation, the pellet was resuspended with $10 \mathrm{~mL}$ of HBSS, and adjusted to the required concentration on the basis of the optical density of the suspension (OD 1.0 at $600 \mathrm{~nm}$ corresponds to about $\left.2.7 \times 10^{8} \mathrm{CFU} / \mathrm{mL}\right)$. The inoculum consisted of $0.5 \mathrm{~mL}$ of the bacterial suspension adjusted to $20000 \mathrm{cfu} / \mathrm{mL}$, in a $1 \mathrm{~mL}$ disposable syringe fitted with a blunt-ended cannula. Extra-inocula were prepared and $50 \mu \mathrm{L}$ of their content plated on blood agar to retrospectively check the size of the infectious dose by counting cfu after overnight incubation at $37{ }^{\circ} \mathrm{C}$. The inoculum was found to contain about $16000 \mathrm{cfu}$.

Healthy lactating multiparous goat does of Alpine breeds were selected on the basis of the absence of intramammary infections and milk cell concentration less than 200000 cells $/ \mathrm{mL}$. They were housed in a barn on a straw bed in groups of about six animals for several months, and were maintained together with their kids which were allowed free suckling. The care and use of goats conformed to the practices in effect at the INRA Nouzilly Research Center. Challenge exposure was carried out within 2 to 4 months after kidding. Bacteriological examination of milk (half-gland foremilk) was done with a standard procedure [13] one week before inoculation, on the day of inoculation, every other day up to two weeks post-inoculation (pi), then twice a week up to the end of the experiment (4 weeks).

To induce intramammary infections, goats were infused through the teat canal with $0.5 \mathrm{~mL}$ of the bacterial suspension within one hour of preparation. Before infusion, teats were swabbed with $70 \%$ ethanol, and were gently massaged upwards after infusion. One udder half was inoculated, the other one serving as the control gland. The goats were hand-milked before infusion, and the kids were kept away from the inoculated goats for at least $3 \mathrm{~h}$ after inoculation.

\subsection{Processing of milk samples}

Milk samples were taken with asepsis precautions for bacteriological examination and determination of cell content (number and microscopic appearance). Bacterial shedding in milk was semiquantitatively assessed by recording the number of bacterial colonies in $50 \mu \mathrm{L}$ milk plated on sheep blood esculine agar plates after $24 \mathrm{~h}$ of incubation at $37{ }^{\circ} \mathrm{C}$. Within $2 \mathrm{~h}$ of sample collection, slides were prepared to microscopically assess the appearance of milk cells. Milk $(100 \mu \mathrm{L}+30 \mu \mathrm{L}$ fetal bovine serum) was cytocentrifuged (Shandon Southern centrifuge, Shandon Inc. Pittsburgh, PA, USA) and the slides were stained with May-Grünwald-Giemsa before examination under the microscope. Another portion $(500 \mu \mathrm{L})$ was used for cell count which was performed with a Fossomatic model 90 (Foss Electric, Hillerod, Denmark). The remainder of the milk was centrifuged at $1500 \times g$ for $30 \mathrm{~min}$ at $4{ }^{\circ} \mathrm{C}$. The cream was discarded, and the skimmed milk was stored in portions at $-20{ }^{\circ} \mathrm{C}$.

\subsection{Quantitation of leucotoxin components in milk by ELISA}

ELISA were performed in 96-well flatbottomed plates (Nunc Immunoplate Maxisorp, Merck Eurolab, Strasbourg, France). Following each incubation step, three washes were carried out with phosphate buffered saline (PBS) supplemented with $0.05 \%$ Tween 20, using a MW 96/384 microplate washer (Beckman Coulter Inc., Fullerton, CA, USA). Samples and immune reagents were diluted in PBS containing $0.5 \%$ gelatin and phenol red unless 
otherwise stated. Appropriate dilutions of the immune reagents were dispensed in $100 \mu \mathrm{L}$ samples and incubated at $37^{\circ} \mathrm{C}$ for $1 \mathrm{~h}$ unless otherwise stated.

Sandwich ELISA were used to measure the concentrations of LukM and LukF'. The sequence of incubation steps was as follows: (1) coating of the plate with affinity-purified bovine anti-LukM or anti-LukF' $(5 \mu \mathrm{g} / \mathrm{mL})$ in carbonatebicarbonate buffer $0.1 \mathrm{M} \mathrm{pH} 9.6$ overnight at $4{ }^{\circ} \mathrm{C}$; (2) blocking with $0.5 \%$ gelatin for $30 \mathrm{~min}$; (3) incubation with milk samples undiluted or diluted $1 / 4$, along with serial dilutions of purified LukM or LukF' to establish the standard curve; (4) incubation with rabbit anti-LukM or anti-LukF' immune serum diluted 1/1000; (5) incubation with peroxidase-conjugated goat antibody to rabbit IgG (Jackson Immunoresearch Laboratories, West Grove, PA, USA) diluted $1 / 10000$; (6) incubation with a $2 \%$ dilution of 2,2'-azino-bis(3ethylbenzthiazoline-sulfonate) (ABTS; Sigma) in $0.1 \mathrm{M}$ citrate buffer $\mathrm{pH} 4.2$, with the addition of $0.075 \%$ hydrogen peroxide just before use. The optical density was read at $414 \mathrm{~nm}$ on a microplate reader (BioKinetics reader; BioTek Instruments, Winooski, VT, USA). Values expressed in $\mathrm{ng} / \mathrm{mL}$ were extrapolated using linear regression from the standard curve obtained with the known concentrations of LukM or LukF'.

\subsection{Titration of leucotoxic activity in milk and neutralization by specific antibodies}

The assay is based on the shape change (spreading) induced on PMN by staphylococcal leucotoxins, as described by $[1,16]$. PMN were isolated from goat blood as described [1], and adjusted to $2 \times 10^{6} / \mathrm{mL}$ in RPMI 1640 without bicarbonate, with $20 \mathrm{mM}$ Hepes (Sigma) and $1 \mathrm{mg} / \mathrm{mL}$ bovine serum albumin (low endotoxin, Uptima Interchim, Montluçon, France). Via- bility of PMN was higher than $98 \%$ (exclusion of trypan blue) and more than $95 \%$ of cells were granulocytes. Flat-bottomed 96-well microtiter plates were coated with $1 \mathrm{mg} / \mathrm{mL}$ BSA in HBSS for $15 \mathrm{~min}$ at $37{ }^{\circ} \mathrm{C}$. After washing, $80 \mu \mathrm{L}$ of serial twofold dilutions of the sample under test were distributed in the wells of the plate, $20 \mu \mathrm{L}$ of PMN suspension was added, and the plate was incubated at $37^{\circ} \mathrm{C}$ for $60 \mathrm{~min}$. Then, the shape of PMN was examined with an inverted microscope. The inverse of the last dilution inducing the spreading of more than $90 \%$ of the cells was taken as the leucotoxic titer. Positive control was carried out with purified LukM/F' (2 nM) and negative control with RPMI 1640.

Neutralization of the leucotoxic activity of milk samples was achieved by adding affinity-purified rabbit $\mathrm{Ab}$ against LukM and LukF' [16], and incubating for $4 \mathrm{~h}$ at $4{ }^{\circ} \mathrm{C}$ before performing the PMN spreading assay. Control of specificity was carried out by incubating the milk samples with the same concentration (see Results) of affinity-purified rabbit $\mathrm{Ab}$ to hen ovalbumin.

\subsection{Quantitation of Ab to LukM and LukF' by ELISA}

Antibodies to LukM and to LukF' were titrated in milk and sera with indirect ELISA. Washings, diluting buffer and incubations were as for the leucotoxin components ELISA. The sequence of incubation steps was as follows: (1) coating of the plate with $2 \mu \mathrm{g} / \mathrm{mL}$ of either purified LukM or LukF' [16] in carbonate-bicarbonate buffer $0.1 \mathrm{MpH} 9.6$; (2) blocking with $0.5 \%$ gelatin for $30 \mathrm{~min}$; (3) incubation with sera diluted $1 / 500$ or milk diluted $1 / 4$, along with serial dilutions of immune goat serum to establish the standard curve; (4) incubation with rabbit anti-LukM or anti-LukF' immune serum diluted 1/1000; (5) incubation with $1 / 10000$ dilution of peroxidase-conjugated rabbit antibody to 
goat IgG (Jackson Immunoresearch Laboratories); (6) ABTS substrate. The optical density was read at $414 \mathrm{~nm}$ on a microplate reader (BioKinetics reader). Caprine sera and milk were titrated in units by extrapolation, using linear regression, from the standard curve obtained with the dilutions of the immune serum which was arbitrarily assigned $10000 \mathrm{Ab}$ units. To obtain this serum, a goat was immunized three times at two-month intervals with $50 \mu \mathrm{g}$ of LukM and LukF' (in separate preparations) emulsified in incomplete Freund's adjuvant. The two toxin components were injected subcutaneously at separate sites. Serum was obtained two weeks after the last injection.

\subsection{Assay of neutralizing activity of serum or milk}

The capacity of serum or milk to neutralize the cytotoxic activity of LukM/LukF' was measured with the PMN spreading assay. The mixture (ratio 1/1) of $50 \mu \mathrm{L}$ LukM and LukF' at $4 \mathrm{nM}$ concentration was incubated for $1 \mathrm{~h}$ at $37{ }^{\circ} \mathrm{C}$ with serial twofold dilutions $(50 \mu \mathrm{L})$ of serum in wells of 96-well microtiter plates. Then, $20 \mu \mathrm{L}$ of caprine PMN suspension $\left(2 \times 10^{6} / \mathrm{mL}\right)$ were added, and the plate was incubated for $1 \mathrm{~h}$ at $37{ }^{\circ} \mathrm{C}$ at rest. Visual assessment of the spreading of PMN was done under an inverted microscope. The inverse of the last dilution of serum precluding the toxin-induced spreading of PMN was taken as the neutralizing titer. A positive control was performed with immune goat serum. The immune serum neutralized $2 \mathrm{nM}$ LukM/F' up to the $1 / 400$ dilution. Owing to its opacity, normal milk had to be diluted at least four times to allow visual assessment of PMN spreading, but serum-like mammary secretion could be tested undiluted.

\subsection{Statistical analysis}

The results were analyzed with the StatXact 5 software (Cambridge, MA,
USA), using the permutation test for paired samples and Spearman correlation (exact nonparametric inference).

\section{RESULTS}

\subsection{Clinical signs}

Mild mastitis symptoms were evoked by intramammary inoculation of about $16000 \mathrm{cfu}$ of $S$. aureus ch122 in 5 of the 6 goats. There were local signs of moderate intensity (sensitive to palpation) during the day following the challenge, then no local or systemic clinical signs. One goat (1214) developed a severe form of mastitis, with local and systemic signs as early as $12 \mathrm{~h}$ pi. At $24 \mathrm{~h}$ pi, the inoculated gland was swelled, red, tender, and there were numerous clots in the milk. At $48 \mathrm{~h}$ pi, a blue skin circular area (about $7 \mathrm{~cm}$ in diameter) was visible at the rear of the gland, signalling a case of gangrenous (necrotic) mastitis. The decision was made to slaughter the animal for ethical reasons. The mammary secretion at this time was serum-like.

\subsection{Inflammatory response and shedding of bacteria}

It was not possible to determine precisely the cell concentration in the milk of the goat (1214) which developed gangrenous mastitis, because of massive clotting, nevertheless cell concentrations of the liquid phase markedly increased as early as day 1 pi (Fig. 1). Cell concentrations increased sharply in the five inoculated glands which developed mild mastitis on the day after inoculation. Thereafter, the course of infection differed widely among animals (Fig. 1). Cell concentrations remained elevated in the milk of two goats but declined in the milk of the other three. One goat got rid of the infection very early (goat 1398): bacteria were not isolated from milk after day 2 pi. Goat 1389 never shed cultivable $S$. aureus, despite a 


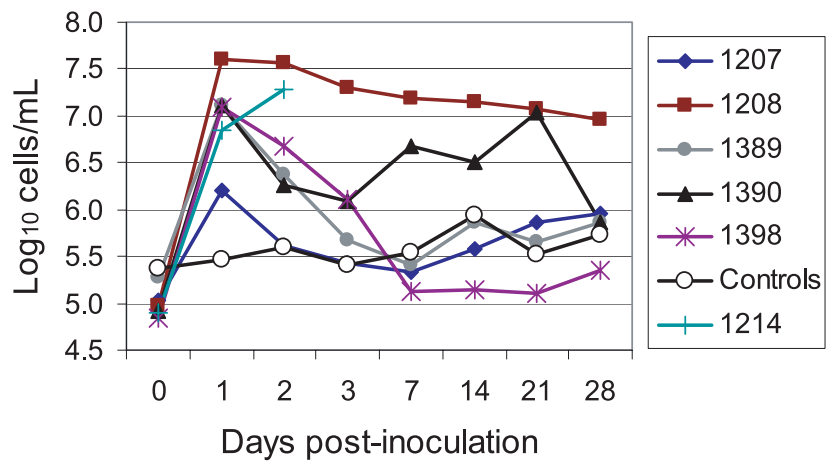

Figure 1. Log cells in milk of inoculated mammary glands of the five goats that developed mild clinical mastitis. Control values are the means of the non-inoculated gland of the same goats. (Please consult www.vetres.org for a colour version of this figure.)

strong initial cellular response in milk, suggesting that bacteria multiplied initially in the gland but were promptly eliminated. Pure cultures of $S$. aureus were consistently recovered from milk of the other three goats until the end of the experiment. The highest shedding of $S$. aureus occurred in the milk of goat 1214, with bacterial concentration $>100000 \mathrm{cfu} / \mathrm{mL}$. The second highest shedding was by goat 1208 . At day $1 \mathrm{pi}$, the shedding was more than $10000 \mathrm{cfu} / \mathrm{mL}$, about $5000 \mathrm{cfu} / \mathrm{mL}$ at day $2 \mathrm{pi}$, and only $1500 \mathrm{cfu} / \mathrm{mL}$ at day 3 pi. In milk samples of the other goats, the concentration of bacteria remained below $1000 \mathrm{cfu} / \mathrm{mL}$.

\subsection{Leucotoxin in milk of $S$. aureus- infected glands}

The milk was searched for leucotoxin by means of sandwich ELISA. With the LukM-ELISA, capable of detecting $0.4 \mathrm{ng}$ of toxin per $\mathrm{mL}$, all the milk samples were negative, except four samples from infected glands of goats 1208 and 1214 . Concentrations of 4.8 and $6.2 \mathrm{ng} / \mathrm{mL}$ were found in the milk of goat 1208, and 140 and $180 \mathrm{ng} / \mathrm{mL}$ in the milk of goat 1214 , at days 1 and 2 pi, respectively. The component LukF' was also detected in these samples, at concentrations comparable to that of LukM (203 ng/mL in milk of goat 1214 at day 2 pi).

At day 2 pi, the milk of goat 1214, which suffered from gangrenous mastitis, was examined microscopically. A cytospin preparation and May-GrünwaldGiemsa staining showed cells with swelled rounded nucleus, and no intact neutrophils (Fig. 2). This cell appearance contrasted with the intact morphology of neutrophils in the milk of the infected glands of the other goats, but was quite comparable to that of blood neutrophils treated in vitro with LukM/LukF' leucotoxin (Fig. 2).

The cytotoxic activity was titrated in milk of goat 1214 at day 2 pi by the PMN spreading assay. Activity was seen up to dilution $1 / 20$, which corresponds to $180 / 20=9 \mathrm{ng} / \mathrm{mL}$ of leucotoxin. Affinitypurified antibodies to LukM and LukF' were used to check that the spreading activity was due to a member of the leucotoxin family. A molar ratio of 10 to 1 was chosen to attempt blocking the toxin activity: antibodies to LukM were added to the milk sample at a final concentration of $10 \mu \mathrm{g} / \mathrm{mL}$, along with $10 \mu \mathrm{g} / \mathrm{mL}$ of antibodies to LukF', and the mixture was incubated for $4 \mathrm{~h}$ at $4{ }^{\circ} \mathrm{C}$ before addition of caprine neutrophils. Antibodies totally inhibited the spreading of neutrophils, even 


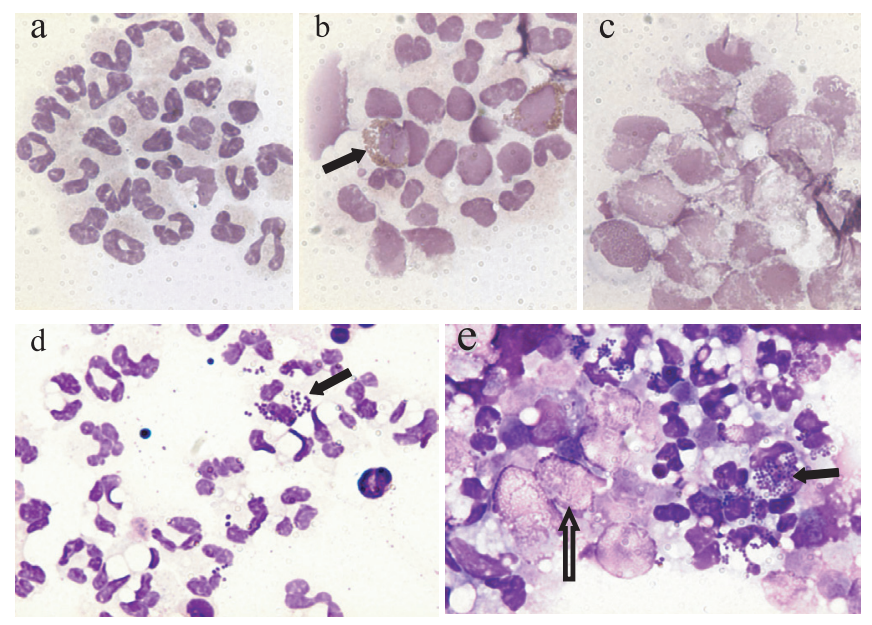

Figure 2. Appearance of PMN subjected to LukM/F' and of cells in milk of gangrenous mastitis. $(a, b, c)$ Effect of LukM/F' on granulocytes (mainly neutrophils) on nucleus appearance. Granulocytes were incubated with $\mathrm{LukM} / \mathrm{F}^{\prime}(2 \mathrm{nM})$ during $0 \mathrm{~min}(\mathrm{a}), 5 \mathrm{~min}$ (b) and $30 \mathrm{~min}$ (c) before cytocentrifugation and May-Grünwald-Giemsa staining. Arrow in (b) points to an eosinophil. (d) the appearance of cells in the milk of goat 1208 at day 2 pi (mild mastitis); most cells are neutrophils with normal appearance. (e) appearance of cells in the milk of goat 1214 (gangrenous mastitis) on day 2 pi. A few intact neutrophils are seen among numerous cells with altered nucleus. Small arrows point to bacterial aggregates. The biggest arrow points to an altered nucleus. (Please consult www.vetres.org for a colour version of this figure.)

in undiluted milk. Anti-ovalbumin antibodies $(20 \mu \mathrm{g} / \mathrm{mL}$, final concentration) did not inhibit the activity of milk, which remained able to induce neutrophil spreading at the 1/20 dilution. Cytocentrifugation and May-Grünwald-Giemsa staining was performed to check the morphology of the neutrophil nucleus. The results corresponded to the characteristic alteration provoked by leucotoxins, and the cytotoxic effect was inhibited by antibodies to LukM/F' but not by antibodies to ovalbumin (not shown) in milk samples of goat 1214. Altered cells were also seen in the milk sample of goat 1208 at day 1 pi (not shown), but not at day 2 pi (Fig. 2).

\subsection{Antibody response to infection: leucotoxin ELISA titers}

Before infection, $\mathrm{Ab}$ to the two components of the toxin were detected in the serum of the six goats, with wide variations among animals (Fig. 3). Ab titers in serum of goat 1214 before inoculation were comparable to the titers of other goats, 356 and 48 for $\mathrm{Ab}$ anti-LukM and anti-LukF', respectively. Only three goats developed $\mathrm{Ab}$ titers higher than pre-infection titers. Titers began to increase at days $7 \mathrm{pi}$, and a peak was reached at day 21 pi. Titers remained low in the serum of the two goats that eliminated precociously their infection (No. 1389 and 1398). The highest titers were in the serum of goat 1208 , which had the highest numbers of bacteria in milk. Differences between anti-LukM or anti-LukF' ELISA titers at day 0 versus either day 14,21 or 28 pi were statistically significant ( $p=0.03$; permutation test for two related samples).

In milk, initial $\mathrm{Ab}$ titers were very low, from $1 / 2000$ to $1 / 9250$ of serum titers. In the milk of inoculated glands, there was 

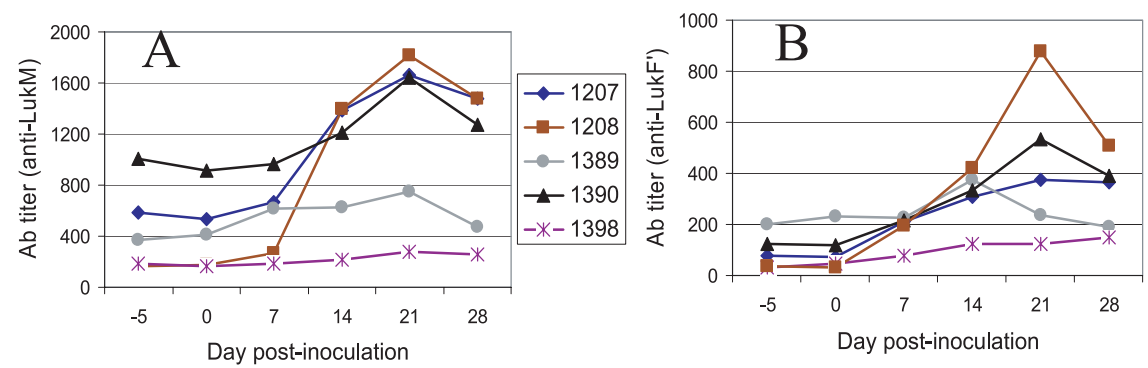

Figure 3. Antibody ELISA titers in serum of the five goats which developed mild clinical mastitis. (A) Ab to LukM as the antigen. (B) Ab to LukF' as the antigen. Titers were calcutated with reference to a standard immune goat serum which was given arbitrarily 10000 ELISA units. Titers at day 0 differed significantly from titers at days 14,21 or 28 ( $p=0.031$; permutation test for paired samples, one-sided). (Please consult www.vetres.org for a colour version of this figure.)

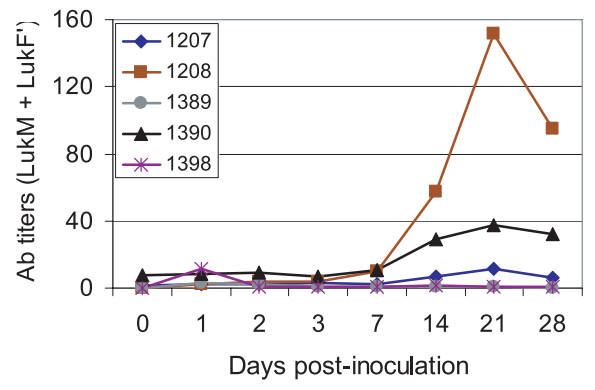

Figure 4. Mean Ab ELISA titers (LukM + LukF') in milk of inoculated glands of the 5 individual goats. Titers of $\mathrm{Ab}$ to LukM and to LukF' were added for each sample. Titers at day 0 differed significantly from titers at days 14,21 or 28 ( $p=0.031$; permutation test for paired samples, one-sided). (Please consult www.vetres.org for a colour version of this figure.)

a slight initial increase in $\mathrm{Ab}$ titers on day 1 pi, probably as a result of the exudation of plasma associated with the inflammatory response. Nevertheless, marked increases in titers were not seen before day 14 pi and later on (Fig. 4), probably at least partly as a result of combined exudation of plasma and of increases in blood $\mathrm{Ab}$ titers. As in serum, the Ab titers did not augment in the milk of the goats 1289 and 1398 (Fig. 4). Differences between ELISA titers (anti-LukM + antiLukF') in the milk of inoculated glands at day 0 versus either day 14,21 , or 28 pi were statistically significant ( $p=0.03$; permutation test for two related samples). In control healthy glands, $\mathrm{Ab}$ titers followed an upward trend from day 14 pi, although not significant (Fig. 5). The ratio of $\mathrm{Ab}$ titers after/before infection ranged from 2 to 5 in healthy glands and 10 to 30 in infected glands.

\subsection{Neutralizing antibodies in serum and milk}

The serum of all the goats exerted some neutralizing activity on LukM/F', but it was rather low because undiluted or at least $10 \%$ serum were necessary to block the activity of two times the lowest toxin concentration capable of inactivating neutrophils, i.e. 1-2 nM (18-36 ng/mL) (Fig. 5). In contrast, the serum of the immunized goat inhibited the toxic activity of the toxin up to the $1 / 400$ dilution. At the peak of the ELISA serum $\mathrm{Ab}$ titers, the neutralizing titers were increased (Fig. 6): the median value, which before inoculation was 10 , reached 40 . The correlation between the neutralizing and the ELISA titers were of 0.86 and 0.95 at days 0 and 21 pi ( $p=$ 0.083 ), respectively, suggesting that most 


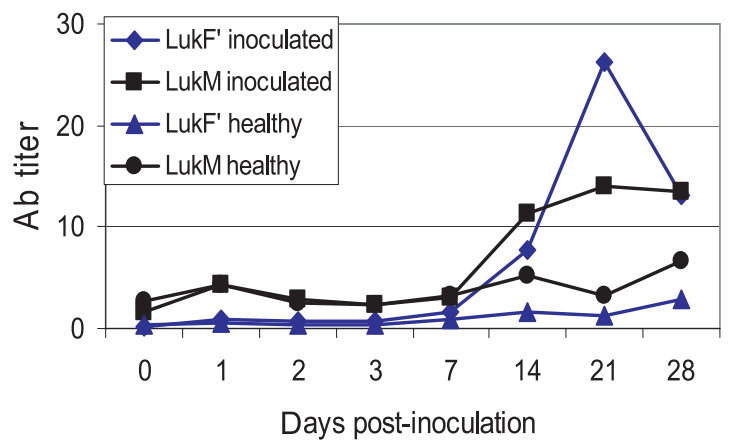

Figure 5. Mean Ab ELISA titers (5 goats) in milk of either inoculated or control healthy glands. Titers are given for each of the two antigens, LukM and LukF'. (Please consult www.vetres.org for a colour version of this figure.)

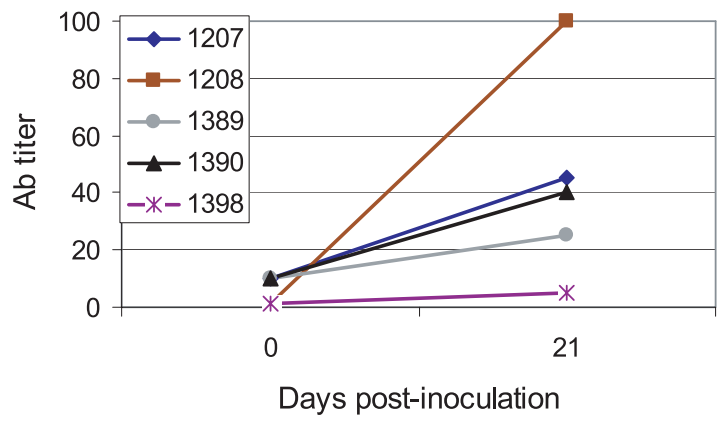

Figure 6. Neutralizing titers of goat serum before and 21 days after inoculation of the mammary gland with $S$. aureus ch122. Titer is the inverse of the serum dilution neutralizing twice the minimum active concentration of LukM/F' (i.e. $36 \mathrm{ng} / \mathrm{mL}$ ) in the PMN spreading assay. Titers at day 0 differed significantly from titers at day 21 ( $p=0.031$; permutation test for paired samples, one-sided). (Please consult www.vetres.org for a colour version of this figure.)

of the induced $\mathrm{Ab}$ were neutralizing. Neutralizing activity was not detected in milk, except in the samples taken 14, 21 and 28 days pi from the inoculated mammary gland of goat 1208, which had the highest milk Ab titers. Nevertheless, only the smallest dilution that can be tested due to the opacity of milk (1/4) was inhibitory.

\section{DISCUSSION}

The main objective of this study was to investigate whether leucotoxins are produced in vivo in the course of mammary infection. Several lines of evidence indicate that this was the case. First, leucotoxin was detected in certain milk samples by ELISA. Second, leucotoxin-specific cytotoxic activity was present in milk samples of a case of gangrenous mastitis. Third, $\mathrm{Ab}$ titers increased in the serum and milk of all the animals that developed lasting infection.

The direct demonstration of intramammary production of leucotoxins by their detection in milk is hindered by the dilution by milk of the minute amounts which are likely to be generated in the foci of 
infection, unless high bacterial concentration are reached in milk where leucotoxin production could then take place. The occurrence of naturally acquired antibodies and potential elicited antibodies could also interfere with immunochemical detection of the toxins. In the present study, both antigenic and cytotoxic leucotoxin activities were found in several samples of milk during infection. Twenty times the minimal concentration active on caprine PMN was found in mammary secretion during the case of gangrenous mastitis, along with massive shedding (more than $10^{5} \mathrm{cfu} / \mathrm{mL}$ ) of staphylococci.

Others have reported the detection of leucotoxin in milk samples from cows with chronic staphylococcal mastitis, but not leucotoxic activity by milk from infected glands [11]. In the present study, cytotoxic activity was found in milk of gangrenous mastitis. The inhibition of this cytotoxic activity by specific but not by unrelated $\mathrm{Ab}$ demonstrated that it was due to a toxin belonging to the family of binary staphylococcal leucotoxins and not to another staphylococcal cytotoxin such as a hemolysin or delta-toxin. The cytotoxic activity found in milk of gangrenous mastitis was high, since this milk withstood a twenty-fold dilution before loosing its effect on caprine neutrophils. This finding agreed with the appearance in the milk samples of cells which showed the alterations characteristic of leucotoxin activity (Fig. 2). The identity of the leucotoxin detected in milk cannot be ascertained only on the basis of ELISA, because of the cross-reactivity of $\mathrm{Ab}$ due to sequence identity between class $\mathrm{S}$ components (55 to $72 \%$ ) and class $\mathrm{F}$ components (71 to $79 \%$ ), respectively [14]. Nevertheless, it is probable that the major leucotoxin in positive samples was LukM/LukF', for two reasons. First, S. aureus Ch122 essentially produces this leucotoxin [16]. Second, the robust cytotoxic activity of milk of gangrenous mastitis strongly suggests that the leucotoxin produced was indeed LukM/F', because at the least active concentration $(9 \mathrm{ng} / \mathrm{mL}$ in the $1 / 20$ dilution), none of the other leucotoxins are active on caprine neutrophils, since they are at best 10 times less active than LukM/F' [1]. In fact, the toxin in milk seemed to be even slightly more efficient than purified LukM/F', which is active down to about $18 \mathrm{ng} / \mathrm{mL}$ on caprine neutrophils ([16] and this study). Possibly other toxins, such as hemolysins, secreted in milk along with leucotoxins, contributed to this strong activity.

Indirect evidence that leucotoxins were generated in vivo was the increases in antibody titers during or following infection, assuming that rising titers result from the production of the corresponding antigen by the mastitis-causing bacteria. The sharp rises in $\mathrm{Ab}$ titers which occurred in the 14 days following infection (Fig. 3) indicate that leucotoxins were produced in vivo. Persistence of infection was necessary to elicit $\mathrm{Ab}$, since the two goats that eliminated staphylococci from the inoculated gland within 2 days after inoculation did not develop Ab. On the contrary, mild mastitis cases, associated with moderate shedding of bacteria, were sufficient to induce $\mathrm{Ab}$, although bacterial multiplication was insufficient for $\mathrm{Ag}$ to be detected in most milk samples. Higher leucotoxin $\mathrm{Ab}$ ELISA values in milk and serum of cows with naturally acquired $S$. aureus mastitis than in mastitis-free cows has been reported [10]. This suggests that chronic infections, mainly subclinical, elicit Ab responses to leucotoxins also in cattle. A parallel can be made with another potential virulence factor of mastitis-causing $S$. $a u$ reus, enterotoxin D. This enterotoxin was recently shown to be produced in vivo and was found in the milk of a few infected cows, at concentrations active on bovine lymphocytes [19]. Specific Ab were elicited, which were able to neutralize the toxin. From these results and those of 
the present study, it can be put forward that during chronic mammary infections, although subclinical during most of their duration, toxins are produced which are capable of eliciting systemic Ab responses.

Outcomes of infections ranged from prompt elimination without clinical signs to gangrenous mastitis. The group of inoculated goats was not very homogeneous, and the conditions of their rearing did not preclude contact with $S$. aureus prior to inoculation. This may account for the heterogeneity of the responses to infection. No clear association between Ab titers before inoculation and severity of mastitis was obvious in this study.

The possession of $l u k P V$ genes by isolates of human origin appears to be associated with increased severity, ranging from severe cutaneous infection to necrotizing pneumonia $[5,8]$. It may be that LukM/F', which is the most active leucotoxin on ruminant PMN, as the Panton-Valentine leucocidin is on human PMN, contributes to the severity of mastitis. The leucotoxin LukM/F' seems to be an attribute of strains isolated from mastitis of ruminants, since it is not present in the genome of strains isolated from other hosts [20,21]. Recently, it has been shown that staphylococcal exosecretion containing LukM/F' can provoke an inflammatory reaction when infused in the mammary gland [22], suggesting that this leucotoxin can play a part in the severity of the inflammatory response. The in vivo production of $\mathrm{LukM} / \mathrm{F}^{\prime}$ is a prerequisite for a contribution to pathogenesis, and the present study brings arguments that support this production during mammary infection. Moreover, the observed case of gangrenous (necrotic) mastitis suggests that LukM/F' could play a role in this syndrome. It can be hypothesized that when the population of a high-leucotoxinproducing strain reaches a sufficient size in the mammary gland, leucotoxin is produced in amounts that overwhelm the natural neutralizing Ab. Then phagocytic defenses are altered, and bacteria multiplication escapes control. Accordingly, the conditions would be met for gangrenous mastitis to develop. This hypothesis would be worth testing with a mutant strain defective in LukM production.

In conclusion, this study shows that the lukM gene was functional, and actively transcribed and translated in the course of mammary infection. Leucotoxin and cytotoxic activity were found in a few milk samples, and this activity was inhibited by $\mathrm{Ab}$ to $\mathrm{LukM} / \mathrm{F}$ '. Antibody titers increased when mammary infection lasted more than a few days. In a case of gangrenous mastitis, milk cells displayed the characteristic appearance of neutrophils incubated with purified LukM/F'. It can be concluded that leucotoxin, most likely LukM/F', was produced during mammary infection, and the high leucotoxic activity found in gangrenous mastitis secretion suggests that this toxin could play a role in the pathogenesis of severe forms of mastitis.

\section{ACKNOWLEDGEMENTS}

The author thanks Philippe Bernardet and the staff of animal experimental facilities for managing the goats and collecting blood and milk samples, and Florence B. Gilbert (IASP) for fruitful discussions and critical reading of the manuscript.

\section{REFERENCES}

[1] Barrio M.B., Rainard P., Prevost G., LukM/LukF'-PV is the most active Staphylococcus aureus leukotoxin on bovine neutrophils, Microbes Infect. (2006) 8:2068-2074.

[2] Bergonier D., de Cremoux R., Rupp R., Lagriffoul G., Berthelot X., Mastitis of dairy small ruminants, Vet. Res. (2003) 34:689-716.

[3] Bronner S., Jehl F., Peter J.D., Ploy M.C., Renault C., Arvis P., Monteil H., Prevost G., Moxifloxacin efficacy and vitreous penetration in a rabbit model of 
Staphylococcus aureus endophthalmitis and effect on gene expression of leucotoxins and virulence regulator factors, Antimicrob. Agents Chemother. (2003) 47:1621-1629.

[4] Contreras A., Luengo C., Sanchez A., Corrales J.C., The role of intramammary pathogens in dairy goats, Livest. Prod. Sci. (2003) 79:273-283.

[5] Etienne J., Panton-Valentine leukocidin: a marker of severity for Staphylococcus aureus infection? Clin. Infect. Dis. (2005) 41:591-593.

[6] Fueyo J.M., Mendoza M.C., Rodicio M.R., Muniz J., Alvarez M.A., Martin M.C., Cytotoxin and pyrogenic toxin superantigen gene profiles of Staphylococcus aureus associated with subclinical mastitis in dairy cows and relationships with macrorestriction genomic profiles, J. Clin. Microbiol. (2005) 43:1278-1284.

[7] Genestier A.L., Michallet M.C., Prevost G., Bellot G., Chalabreysse L., Peyrol S., Thivolet F., Etienne J., Lina G., Vallette F.M., Vandenesch F., Genestier L., Staphylococcus aureus Panton-Valentine leukocidin directly targets mitochondria and induces Baxindependent apoptosis of human neutrophils, J. Clin. Invest. (2005) 115:3117-3127.

[8] Gillet Y., Issartel B., Vanhems P., Fournet J.C., Lina G., Bes M., Vandenesch F., Piémont Y., Brousse N., Floret D., Etienne J., Association between Staphylococcus aureus strains carrying gene for Panton-Valentine leukocidin and highly lethal necrotising pneumonia in young immunocompetent patients, Lancet (2002) 359:753-759.

[9] König B., Prévost G., Piémont Y., König W., Effects of Staphylococcus aureus leukocidins on inflammatory mediator release from human granulocytes, J. Infect. Dis. (1995) 171:607-613.

[10] Loeffler D.A., Norcross N.L., Enzymelinked immunosorbent assay for detection of milk immunoglobulins to leukocidin toxin of Staphylococcus aureus, Am. J. Vet. Res. (1985) 46:1728-1732.

[11] Loeffler D.A., Creasy M.T., Norcross N.L., Paape M.J., Enzyme-linked immunosorbent assay for detection of leukocidin toxin from Staphylococcus aureus in bovine milk samples, J. Clin. Microbiol. (1988) 26:13311334.

[12] Paape M., Mehrzad J., Zhao X., Detilleux J., Burvenich C., Defense of the bovine mammary gland by polymorphonuclear neu- trophil leukocytes, J. Mammary Gland Biol. Neoplasia (2002) 7:109-121.

[13] Poutrel B., Rainard P., Predicting the probability of quarter infection (by major pathogens) from somatic cell concentration, Am. J. Vet. Res. (1982) 43:1296-1299.

[14] Prévost G., The bi-component staphylococcal leucocidins and $\gamma$-haemolysins (toxins), in: Alouf J.E., Freer J.H. (Eds.), The comprehensive sourcebook of bacterial protein toxins, Academic Press, London, 1999, pp. 402-418.

[15] Prévost G., Mourey L., Colin D.A., Menestrina G., Staphylococcal pore-forming toxins, Curr. Top. Microbiol. Immunol. (2001) 257:53-83.

[16] Rainard P., Corrales J.C., Barrio M.B., Cochard T., Poutrel B., Leucotoxic activities of Staphylococcus aureus strains isolated from cows, ewes, and goats with mastitis: importance of LukM/LukF'-PV leukotoxin, Clin. Diagn. Lab. Immunol. (2003) 10:272-277.

[17] Rainard P., Riollet C., Innate immunity of the bovine mammary gland, Vet. Res. (2006) 37:369-400.

[18] Sutra L., Poutrel B., Virulence factors involved in the pathogenesis of bovine intramammary infections due to Staphylococcus aureus, J. Med. Microbiol. (1994) 40:79-89.

[19] Tollersrud T., Kampen A.H., Kenny K., Staphylococcus aureus enterotoxin D is secreted in milk and stimulates specific antibody responses in cows in the course of experimental intramammary infection, Infect. Immun. (2006) 74:3507-3512.

[20] Von Eiff C., Friedrich A.W., Peters G., Becker K., Prevalence of genes encoding for members of the staphylococcal leukotoxin family among clinical isolates of Staphylococcus aureus, Diagn. Microbiol. Infect. Dis. (2004) 49:157-162.

[21] Yamada T., Tochimaru N., Nakasuji S., Hata E., Kobayashi H., Eguchi M., Kaneko J., Kamio Y., Kaidoh T., Takeuchi S., Leukotoxin family genes in Staphylococcus aureus isolated from domestic animals and prevalence of lukM-lukF-PV genes by bacteriophages in bovine isolates, Vet. Microbiol. (2005) 110:97-103.

[22] Younis A., Krifucks O., Fleminger G., Heller E.D., Gollop N., Saran A., Leitner G., Staphylococcus aureus leucocidin, a virulence factor in bovine mastitis, J. Dairy Res. (2005) 72:188-194. 